\title{
Stressors in patients of neonatal intensive care unit
}

\author{
Fontes estressoras em pacientes de unidade de terapia intensiva neonatal
}

Samuel Oliveira da Vera ${ }^{1}$, Márcia Teles de Oliveira Gouveia ${ }^{1}$, Amanda Lúcia Barreto Dantas ${ }^{1}$, Silvana Santiago da Rocha $^{1}$

Objective: to analyze the stressors on patients in neonatal intensive care unit. Methods: a cross-sectional study, develop in a reference public maternity hospital, with 60 nursing professionals who cared for the 24 hospitalized newborn babies. For data collected, a sociodemographic questionnaire and the Stressor Scale in Intensive Care Units were used to identify the stressors. A value of $\mathrm{p}<0.05$ was used for the tests. Results: of the total of professionals, $18(30.0 \%)$ were nurses. Most of the newborns were premature-moderate, with hospitalization time between eight and 15 days. Being punctured by needles was the most stressful factor and silencing alarms the main action mentioned as a strategy to reduce stressors. Conclusion: the 15 stressors evaluated presented high mean scores, showing that neonatal intensive care unit is an environment that varies between stressful and very stressful for newborns.

Descriptors: Intensive Care Units, Neonatal; Infant, Newborn; Noise; Lighting; Stress, Mechanical.

Objetivo: analisar as fontes estressoras em pacientes de unidade de terapia intensiva neonatal. Métodos: estudo transversal, desenvolvido em maternidade pública de referência, com 60 profissionais de enfermagem que prestaram cuidados aos 24 recém-nascidos internados. Para coleta de dados, foi utilizado questionário sociodemográfico e Escala de Estressores em Unidades de Terapia Intensiva, esta para identificação dos fatores estressores. Foi adotado valor de $\mathrm{p}<0,05$ para os testes. Resultados: do total de profissionais, $18(30,0 \%)$ eram enfermeiros. A maior parte dos recém-nascidos era prematuro-moderado, com tempo de internação entre oito e 15 dias. Ser furado por agulhas foi o fator de maior estresse e silenciar alarmes a principal ação mencionada como estratégia de redução de fatores estressores. Conclusão: as 15 fontes estressoras avaliadas apresentaram escores médios elevados, mostrando que a unidade de terapia intensiva neonatal se configura como ambiente que varia entre estressante e muito estressante para recém-nascidos.

Descritores: Unidades de Terapia Intensiva Neonatal; Recém-Nascido; Ruídos; Iluminação; Estresse Mecânico.

${ }^{1}$ Universidade Federal do Piauí. Teresina, PI, Brazil. 


\section{Introduction}

The environment with intense sensorial stimulation of the neonatal intensive care units can compromise the process of development and growth of newborns, due to the fact that these, especially the premature ones, have extremely sensitive sensory receptors. In addition to the harm caused to the neonates, these stimuli can also cause physiological and psychological changes in the parents who attend this environment, as well as in the team of professionals working in this environment ${ }^{(1)}$.

In newborns, this exposure can cause hearing loss, disturbance in sleep patterns, irritability, agitation, crying, fatigue, increased oxygen consumption and heart rate, compromising the healing process; in professionals, it can lead to fatigue, headache, low concentration, irritability, hypertension, heart rhythm disturbance, hearing loss, mood swings, psychiatric disorders and stress; in parents, such levels can cause physiological and behavioral stress, sensory overload, and make it difficult to interact with the newborn ${ }^{(2)}$.

These changes in newborns are related to the environment of the neonatal intensive care unit, as it is different from the intrauterine environment, comparing temperature, soundness, luminosity, accommodation, such as care provided by frequent interruption of sleep periods and rest, with various procedures and activities, for example, bathing and central catheter insertion of peripheral setting ${ }^{(3)}$.

Since neonatal intensive care units are surrounded by people and equipment, it is necessary that verification of the adequacy of sensory-environmental stimuli is a constant concern on the part of professionals involved in improving the quality of neonatal care and the environment for employees. It is essential that health professionals be alerted to changes in the clinical conditions of exposed patients, in order to reduce them, making the environment more suitable for newborns $^{(4)}$.

Based on the conclusions presented, the follo- wing question emerged: what are the stressors in a neonatal intensive care unit and the strategies adopted by the professionals to reduce them? In order to answer these questions, this study aimed to analyze the stressors in neonatal intensive care unit patients.

\section{Methods}

A cross-sectional study, carried out in a neonatal intensive care unit, of a public maternity hospital, located in the capital city of the State of Piauí, Brazil, which serves the Unified Health System, with a total of 20 beds.

The study population consisted of nursing professionals (nurses, nursing technicians and nursing auxiliaries) who worked and newborns admitted to the neonatal intensive care unit. The census-type sample comprised 60 caregivers of 24 newborns admitted to the neonatal intensive care unit from July to August 2017, when the data collection was performed.

The inclusion criteria of nursing professionals were: to be scheduled to work in the period of data collection, with minimum time of six months in the sector. As exclusion criteria, the fact that the professional is away for vacation and/or medical leaves at the time of data collection. In relation to the newborns the inclusion criterion was the hospitalization time of more than one week in the neonatal intensive care unit.

Two instruments were used to collect data: questionnaire and Scale. The first one contains open and closed questions, consisting of two parts, in which the first considers the sociodemographic variables related to professionals: sex, age, work period, profession, professionals' knowledge of the existence of stressors and their possible negative effects and measures that are capable of reducing them; the second part is composed of sociodemographic and clinical variables related to newborns, such as: sex, gestational age, date of birth, length of hospital stay, weight, height, diet, respiratory support and phototherapy use. 
In order to identify the stressors, it was applied the Intensive Care Unit Environmental Stressor Scale (ICUESS), which is originally composed of 40 items, was applied: (1) non-stressful, (2) little stressful, (3) stressful, (4) very stressful ${ }^{(5)}$. Of the 40 ICUESS items, only 15 were used because the original instrument was develop for adults, and the present study involves stress factors for the neonatal population.

A pilot test was performed, before the collection period, with $10.0 \%$ of the sample of professionals and newborns. From the results of the pilot test, the sociodemographic questionnaires of professionals and newborns were modified regarding the content, to meet the objectives of the study. Pilot participants were not included in the study's final population.

For the ICUESS internal consistency analysis, the Cronbach alpha coefficient was used, which was adequate, with a value of 0.73 , showing uniformity and coherence among the participants' responses. To verify the normality of data distribution, the Kolmogorov-Smirnov normality test was used, which revealed that the data had no normal distribution. Thus, the non-paramedic Mann-Whitney test was used to compare the means between the professional categories for each stressor. For all statistical tests, $\mathrm{p}<0.05$ was used for statistical significance.

The data were typed in Excel 2010 (Windows 7) and submitted to consistency analysis by double typing. After comparing the two spreadsheets typed and correcting the inconsistencies, the data were exported to the Statistical Package for the Social Science program (version 19.0). Subsequently, they were analyzed according to the variables involved, by means of descriptive statistics: absolute and relative frequencies, mean and standard deviation.

The study complied with the ethical and legal precepts of research involving human beings, being approved by the Research Ethics Committee of the Federal University of Piauí, according to report $\mathrm{n}^{\underline{0}}$ 1.872 .445 .

\section{Results}

Of the 60 nursing professionals who participated in this study, 18 (30.0\%) were nurses and 42 (70.0\%) nursing technicians/auxiliaries. In relation to gender, $56(93.3 \%)$ were female. The predominant age group was individuals between 24 and 37 years old, represented by 28 (46.7\%) professionals.

The average age was 40.5 years old, with a standard deviation of 8.7, with a minimum age of 24 years old and a maximum of 60 . Regarding the work shift, 23 (38.3\%) professionals worked only in daytime service. Concerning the working regime, of the 18 participating nurses, four $(6.7 \%)$ were day care workers, two coordinators of the neonatal intensive care unit, the remaining 14 (23.3\%) nurses were on-duty and all 42 (70.0\%) nursing technicians/auxiliaries were on duty. The professionals reported having knowledge of the possible negative effects of stressors in the neonatal intensive care unit. The results are set forth in Table 1.

Table 1 - Sociodemographic and clinical characteristics of the nursing professionals of the Neonatal Intensive Care Unit

\begin{tabular}{lccc}
\hline \multirow{2}{*}{ Variables } & Nurse & $\begin{array}{c}\text { Technician/ } \\
\text { auxiliary }\end{array}$ & Total \\
\cline { 2 - 4 } & n (\%) & n (\%) & n (\%) \\
\hline Gender & $2(3.3)$ & $2(3.3)$ & $4(6.7)$ \\
Male & $16(26.7)$ & $40(66.7)$ & $56(93.3)$ \\
Female & & & \\
Age (years) & $9(15.0)$ & $19(31.7)$ & $28(46.7)$ \\
$24-37$ & $8(13.3)$ & $10(16.7)$ & $18(30.0)$ \\
$38-48$ & $1(1.7)$ & $13(21.7)$ & $14(23.3)$ \\
$49-60$ & & & \\
Work shift & $2(3.3)$ & - & $2(3.3)$ \\
Morning & $1(1.7)$ & - & $1(1.7)$ \\
Afternoon & $1(1.7)$ & $22(36.7)$ & $23(38.3)$ \\
Daytime service & - & $20(33.3)$ & $20(33.3)$ \\
Nighttime service & $14(23.3)$ & - & $14(23.3)$ \\
Daytime nighttime service & & & \\
Working regime & & - & $4(6.7)$ \\
Day shift & $4(6.7)$ & - & $56(93.3)$ \\
On duty & $14(23.3)$ & $42(70.0)$ & $50(100.0)$ \\
Total & $18(30.0)$ & $42(70.0)$ & 6
\end{tabular}


Regarding the sociodemografic characterization, of the 24 newborns found in the neonatal intensive care unit, 14 (58.3\%) were male and 10 (41.7\%) were female. Fifteen (62.5\%) were born with gestational age between 29 and 33 weeks (moderate premature).

The average gestational age was 30.6 weeks, with a standard deviation of 3.6, with a minimum age of 24 weeks and a maximum of 40 weeks. The average hospitalization time was 14.7 days, with a standard deviation of 8.7, with eight days being the minimum period and 36 days the maximum period.

Regarding birth weight, most were classified as moderate-weight and extremely low-weight newborns, with 18 (30\%) newborns. The average weight was $1.299,1$ grams with a standard deviation of 721.5 , presenting a minimum weight of 600 grams and a maximum of 3.650 grams.

Regarding the birth height, the average was 36.7 centimeters, with a standard deviation of 4.3 , with a minimum height of 28 and a maximum of 47 centimeters. About the type of diet, 15 (62.5\%) newborns made use of enteral diet.

Regarding the type of respiratory support, 11 (45.8\%) were intubated, six (25\%) without any type of respiratory support, four (16.7\%) using non-invasive ventilation and three (12.5\%) use of circulating $\mathrm{O}_{2}$ (oxygen). Regarding the use of phototherapy, five (20.8) newborns needed.

Table 2 presents the items of the ICUESS scale in ranking, referring to the average and standard deviation obtained from the nursing professionals who worked in the Neonatal Intensive Care Unit surveyed.

Table 2 - Ranking of the ICUESS items of the scores obtained from nursing professionals in the neonatal intensive care unit

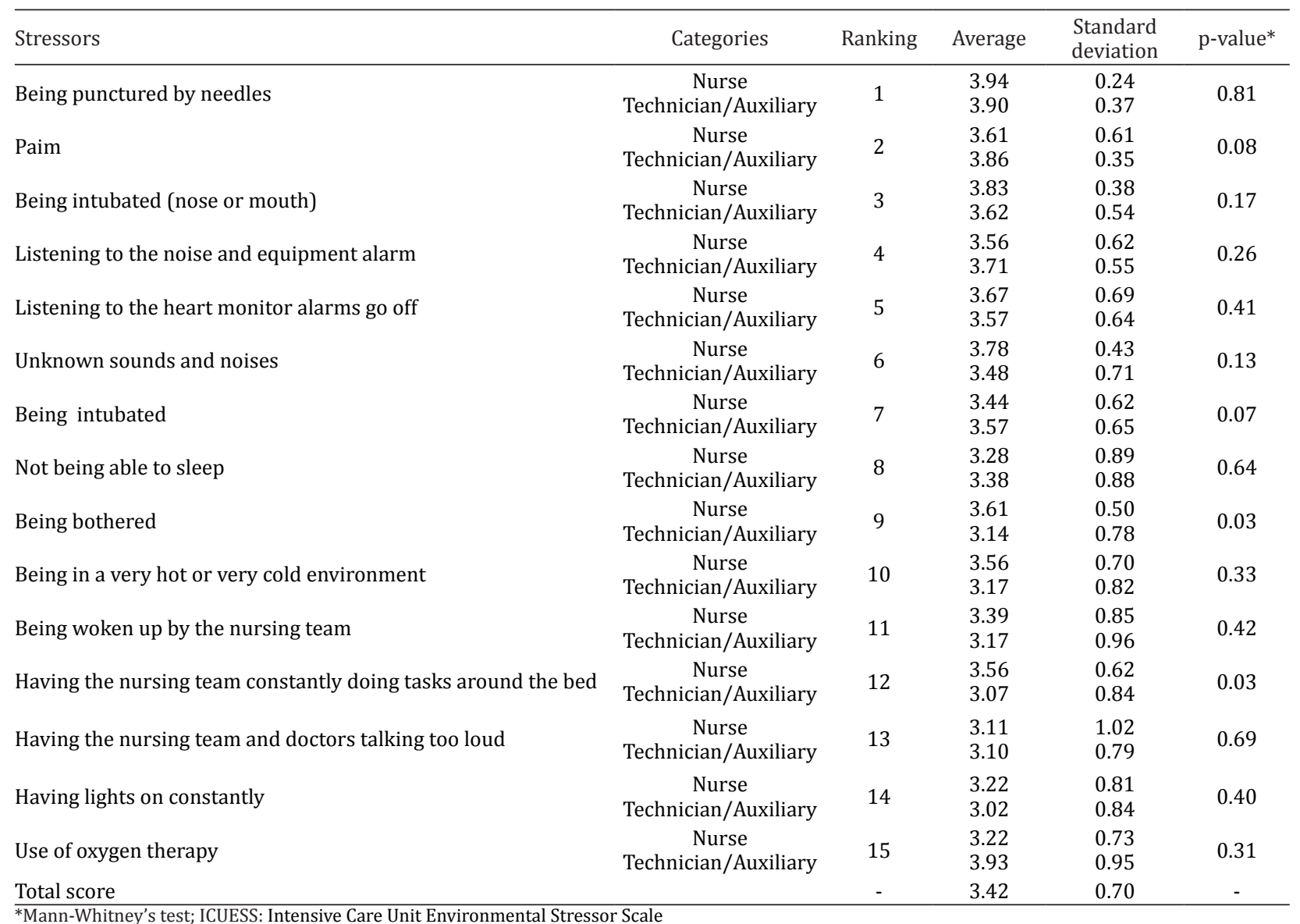


In general, the average responses to the items were high, all of them higher than three, with 3.42 being the general average of the 15 items evaluated. When considering the ICUESS scores, nursing professionals considered the neonatal intensive care unit as an oscillating environment between stressful and very stressful for newborns.

The Mann-Whitney test showed that there was a statistically significant difference between the averages of professionals, in the items "being bothered" and "having the nursing constantly doing tasks around bed", revealing that nursing professionals perceived these items as major sources of stress, when compared to nursing technicians/auxiliaries.

Regarding the main suggestions for reducing stressors in the neonatal intensive care unit, according to the participating nursing professionals, silence was the main action mentioned (35.0\%), followed by health education activities (20.0\%) and equipment maintenance (15.0\%). The reduction of conversations was mentioned by $13.3 \%$ of the participants; while the minimum handling, by $11.7 \%$, only $5.0 \%$ of the participants mentioned the adequacy of lighting as a suggestion of reduction of stressors.

\section{Discussion}

As limitations, it is important not to include the members of other professional categories, to perform the study in a single neonatal intensive care unit and to not use a specific scale for the evaluation of neonatal stressors, so the inferences taken must be addressed with restrictions.

In spite of this, it is presented among the relevance of the study the possibility of sensitizing the nursing professionals to the stressors in the environment, in order to instigate the professional autonomy in the accomplishment of more appropriate conducts before them, in Neonatal Intensive Care Units, guided by scientific evidence. Therefore, it is hoped to contribute to the implementation of actions that can minimize such sources of stress.
In this study, mean gestational ages were 30.6 weeks. A case control study carried out in Chile with moderate and late preterm infants an association between the deficit of psychomotor development, gestational age and neonatal morbidity ${ }^{(6)}$. Morbidity, such as prematurity, can bring respiratory consequences to newborns, aggravating stress levels in a fragile population $^{(7)}$.

Regarding birth weight, most were classified as moderate-low birth weight newborns. Low weight is considered the main factor related to infant morbidity and mortality ${ }^{(8-9)}$. In a cross-sectional population-based study using live births, it was found that newborns with low birth weight had an eight-times greater risk of hospitalization compared to normal-weight newborns ${ }^{(9)}$.

The predominant diet of the newborns was enteral type, by means of an orogastric tube. The most suitable way to stimulate the development of the structures of the stomatognathic system is through oral feeding, since the prolonged use of feeding tube can be harmful to the newborn, since it can after the coordination in the sucking, swallowing and breathing processes, a situation that further favors stress ${ }^{(10)}$.

Most newborns admitted to the neonatal intensive care unit surveyed were intubated. Mechanical pulmonary ventilation is an important therapy in the treatment of several diseases, but it is a very stressful method. Another cohort study, conducted in Rio Grande do Sul, Brazil, with children who needed ventilatory support at birth, warned of the appearance of respiratory complications in the medium term, such as wheezing, asthma and pneumonia, which increased stress levels not only newborns, as well as of the parents $^{(11)}$.

In agreement with the ranking created according to ICUESS's answers, being punctured by needles became the main stressor present in the neonatal intensive care unit surveyed, followed by pain. This perception is due to the performance of tests that require blood collection almost daily. A randomized clinical trial aimed at comparing the pain response in pre- 
term infants who received musical intervention and glucose with a group that did not receive any type of intervention showed that those who received musical intervention and glucose had better results in treatment and recovery, which shows the importance of non-pharmacological methods of pain relief for newborns ${ }^{(12)}$.

The noises were among the main stressors. A study in a neonatal intensive care unit of a Brazilian university hospital that evaluated the noise levels during the three periods of the day corroborates this finding, showing that the noise levels were above the desirable values in the three shifts and interfered negatively in the prognosis of the newborns, becoming a possible stressor for newborns ${ }^{(13)}$.

Being in a very hot or very cold environment is a major stressor for hospitalized newborns. Simple interventions such as maintaining the temperature of air conditioners, monitoring incubator temperature, using plastic bags in case of hypothermia, using hot resuscitation gases are measures that can improve early neonatal survival against cold and/or heat ${ }^{(14)}$.

Having lights on constantly represented one of the less stressful factors, according to the nursing profssionals surveyed. It is noteworthy that artificial and natural lightning plays several roles in a neonatal intensive care unit: it communicates and transmits sensations, provides support to the professionals visual function, regulates circadian function, and therapeutic use $^{(15)}$.

Concerning the suggestions about the stressors, the noise reduction was the main strategy pointed out by the professionals participating in the research. Based on the observation of the adverse effects of high noise levels associated with the neonatal intensive care unit's environment on hospitalized newborns and in order to improve neonatal care, measures such as architectural changes, use of less noisy equipment and the implementation of "sleep time", which is a period of silence, in which it is intended to maintain noise levels within national and international recommendations $^{(16)}$.
Health education activities were cited as a cited of reducing stressors in neonatal intensive care units. Health education is considered by the health professionals as continuous learning and that allows the reflection and problematization of the practice, in addition to approaching the various individuals who are part of care and assisting in the improvement of care. The main difficulty, in general, is related to the operationalization of this, since the lack of interest of professionals, the limited availability of time and insufficient incentive of the managers of the institutions can jeopardize the permanent education in hospital health organizations ${ }^{(17)}$.

\section{Conclusion}

The 15 stressors evaluated in this study had high mean scores, showing that the neonatal intensive care unit is an oscillating environment between stressful and very stressful for newborns. Thus, this study is expected to provide reflections that lead to a new professional perception about the stressors, the negative effects of these and reduction strategies, aiming at risk-free assistance.

\section{Collaborations}

Vera SO contributed in the project design and writing of the article. Dantas ALB and Rocha SS collaborated on designing the Project and relevant critical review of the intellectual content. Gouveia MTO assisted in the relevant critical review of the intellectual content and approval of the final version to be published.

\section{References}

1. Nazario AP. Avaliação dos ruídos em uma unidade neonatal de um hospital universitário. Semina Ciênc Biol Saúde. 2015; 36(1):18998. doi: http://dx.doi.org/10.5433/16790367.2015v36n1Suplp189 
2. Grecco GM, Tsunemi MH, Balieiro MMFG, Kakehashi TY, Pinheiro EM. Repercussion of noise in the neonatal intensive care unit. Acta Paul Enferm. 2013; 26(1):1-7. doi: https://dx.doi. org/10.1590/S0103-21002013000100002

3. Roseiro CP, Paula KMP. Conceptions of humanization of health professionals in Neonatal Intensive Therapy Units. Estud Psicol. 2015; 32(1):10919. doi: https://dx.doi.org/10.1590/0103166X2015000100010

4. Filus WA, Pivatto LF, Fontoura FP, Koga MRV, Albizu EJ, Soares VMN, et al. Noise and its impact on Brazilian hospitals: a literature review. Rev CEFAC. 2014; 16(1):307-17. doi: http://dx.doi. org/10.1590/1982-021620140412

5. Novaes MAFP, Aronovich A, Ferraz MB, Knobel E. Stressors in ICU: patients' evaluation. Intensive Care Med [Internet]. 1997 [cited 2018 Jun. 13]; 23(1):1282-5. Available from: https://www.ncbi. nlm.nih.gov/pubmed/9470087

6. Schonhaut L, Pérez M, Muñoz S. Association between neonatal morbidity, gestational age and developmental delays in moderate to late preterm children. Rev Chil Pediatr. 2015; 86(6):415-25. doi: http://dx.doi.org/10.1016/j.rchipe.2015.08.001

7. Santiago AD, Oliveira MND, Oliveira LL, Pinto Júnior EP. Neonatal morbidity and mortality in Intensive Care Unit. Tempus Actas Saúde Coletiva. 2017; 11(1):141-151. doi: http://dx.doi. org/10.18569/tempus.v11i1.1977

8. Feitosa AC, Santos EFS, Ramos JLS, Bezerra IMP, Nascimento VG, Macedo CC, et al. Fatores associados à mortalidade infantil na região metropolitana do Cariri, Ceará, Brasil. Rev Bras Crescimento Desenvolv Hum. 2015; 25(2):224-229. doi: http://dx.doi.org/10.7322/ JHGD.103019

9. Mucha F, Franco SC, Silva GAG. The frequency and characteristics of mothers and newborns associated with the admission of neonates to ICU in the municipality of Joinville, Santa Catarina 2012-2012. Rev Bras Saúde Mater Infant. 2015; 15(2):201-8. doi: http://dx.doi.org/10.1590/ S1519-38292015000200006
10. Medeiros AMC, Sá TPL, Alvelos C, Novais DSF. Speech therapy in food transition from probe to breast in newborn in kangaroo method. Audiol Commun Res. 2014; 19(1):95-103. doi: http:// dx.doi.org/10.1590/S2317-64312014000100016

11. Chiuchetta FS, Munhoz TN, Santos IS, Menezes AMB, Albernaz E, Barros FC. Neonatal ventilatory support and respiratory diseases in children up to six years of age: the 2004 Pelotas (Brazil) Birth Cohort study. Cad Saúde Pública. 2015; 31(7):1403-15. doi: http://dx.doi. org/10.1590/0102-311X00087614

12. Cruz CT, Gomes JS, Kirchner RM, Stumm EMF. Evaluation of pain of neonates during invasive procedures in intensive care. Rev Dor. 2016; 17(3):197-200. doi: http://dx.doi. org/10.5935/1806-0013.20160070

13. Jordão KR, Pinto LAP, Machado LR, Costa LBVL, Trajano ETL. Possible stressors in a neonatal intensive care unit at a university hospital. Rev Bras Ter Intensiva. 2016; 28(3):310-4. doi: http:// dx.doi.org/10.5935/0103-507X.20160041

14. Melo GM, Cardoso MVLM. Pain in preterm newborns submitted to music and $25 \%$ glucose intervention. Rev Rene. 2016; 18(1):310. doi: http://dx.doi.org/10.15253/21756783.2017000100002

15. Rodrígueza RG, Pattinia AE. Iluminação em unidades de cuidados intensivos neonatais: atualização e recomendações. Arch Argent Pediatr. 2016; 114(4):361-7. doi: http://dx.doi.org/10.5546/ aap. 2016.361

16. Santos BR, Orsi KCSC, Balieiro MMFG, Sato HKTY, Pinheiro ELM. Effect of "quiet time" to reduce noise at the neonatal intensive care unit. Esc Anna Nery. 2015; 19(1):102-6. doi: http://dx.doi. org/10.5935/1414-8145.20150014

17. Puggina CC. Educação permanente em saúde: instrumento de transformação do trabalho de enfermeiros. Rev Espaço Saúde. 2015; 16(4):8797. doi: http://dx.doi.org/10.22421/1517$7130.2015 \mathrm{v} 16 \mathrm{n} 4 \mathrm{p} 87$ 